\title{
Simple Topographic Parameter Reveals the Along- Trench Distribution of Frictional Properties on a Shallow Plate Boundary Fault
}

Hiroaki Koge ( $\square$ koge.h@aist.go.jp)

National Institute of Advanced Industrial Science and Technology https://orcid.org/0000-0002-87204975

\section{Juichiro Ashi}

University of Tokyo

Jin-Oh Park

University of Tokyo

\section{Ayumu Miyakawa}

National Institute of Advanced Industrial Science and Technology Geological Survey of Japan

\section{Suguru Yabe}

National Institute of Advanced Industrial Science and Technology Geological Survey of Japan

\section{Full paper}

Keywords: Subduction zone, Japan Trench, Critical taper model, Frictional variation, Accretionary wedge

Posted Date: October 13th, 2021

DOl: https://doi.org/10.21203/rs.3.rs-948355/v1

License: (1) This work is licensed under a Creative Commons Attribution 4.0 International License. Read Full License

Version of Record: A version of this preprint was published at Earth, Planets and Space on April 21st, 2022. See the published version at https://doi.org/10.1186/s40623-022-01621-6. 


\section{Title page:}

2 Title: Simple topographic parameter reveals the along-trench distribution of

3 frictional properties on a shallow plate boundary fault

4 Author \#1: Hiroaki Koge ${ }^{1}$, koge.h@aist.go.jp as Corresponding author

$5 \quad$ Author \#2: Juichiro Ashi ${ }^{2,3}$, ashi@u-tokyo.aori.ac.jp

6 Author \#3: Jin-Oh Park ${ }^{2}$, jopark@ aori.u-tokyo.ac.jp

$7 \quad$ Author \#4: Ayumu Miyakawa ${ }^{1}$, miyakawa-a@aist.go.jp

$8 \quad$ Author \#5: Suguru Yabe ${ }^{1}$, s.yabe@ aist.go.jp

9

$10{ }^{1}$ Geological Survey of Japan, National Institute of Advanced Industrial Science and

11 Technology, Central 7, 1-1-1 Higashi, Tsukuba, Ibaraki 305-8567, Japan

$12{ }^{2}$ Atmosphere and Ocean Research Institute, The University of Tokyo, 5-1-5

13 Kashiwanoha, Kashiwa-shi, Chiba 277-8564, Japan

$14{ }^{3}$ Department of Natural Environmental Studies Division of Environmental Studies,

15 Graduate School of Frontier Sciences, The University of Tokyo, 5-1-5 Kashiwanoha,

16 Kashiwa-shi, Chiba 277-8564, Japan 


\section{Abstract}

19 The critical taper model of a sedimentary wedge best describes the first-order

20 mechanics of a subduction zone wedge. The tapered wedge geometry, which is

21 conventionally defined by two parameters, the slope angle and the basal dip angle, is

22 responsible for the strength of a megathrust. By applying this theoretical model to

23 subduction zones, fault frictional properties and earthquake occurrences can be

24 compared among subduction zones, and within a single subduction zone, the spatial

25 distribution or temporal change of fault strength can be investigated. The slope angle

26 can be accurately estimated from bathymetry data, but the basal dip angle must be

27 inferred from the subsurface structure, and it requires highly accurate depth-converted

28 seismic reflection profiles. Thus, application of the critical taper model is often limited

29 by a lack of a sufficient number of highly accurate profiles, and the spatial distribution

30 of frictional coefficients must be inferred from relatively few data, generally less than a

31 dozen points. To improve this situation, we revisited the theoretical formula of the

32 critical taper model. We found that the effect of the décollement dip angle $\beta$ on the

33 critical taper model of a sedimentary wedge is negligible when the pore fluid pressure 
34 ratio is high or internal friction is small, conditions which are met in many subduction

35 zones. Therefore, this finding allows frictional variation to be approximated by using

36 only the slope angle variation obtained from the bathymetry. We applied this

37 approximation to the Japan Trench as an example of this approximation, and were able

38 to estimate the friction coefficient distribution on the shallow plate boundary fault from

3971 data points. We found that the area where the friction coefficient was smaller than

40 the mean corresponded to the segment where a large coseismic shallow rupture

41 occurred during the 2011 Tohoku-oki earthquake (Mw 9.0). This result shows that by

42 approximating tapered wedge geometry using a simple topographic parameter that can

43 be obtained from existing global bathymetry, we can quickly estimate the distribution of

44 frictional properties on a plate boundary fault along a trench and related seismic

45 activity.

46

$47 \quad$ Keywords

48 Subduction zone, Japan Trench, Critical taper model, Frictional variation, Accretionary

49 wedge 


\section{Main Text}

\section{Introduction}

The first-order mechanics of a subduction zone wedge, a representative

53 feature of a fold-and-thrust belt, can be clearly explained by the critical taper model

54 (e.g., Dahlen 1990). This geomechanical model, which is based on the Mohr-Coulomb

55 failure criterion, allows frictional properties on a plate boundary fault to be determined.

56 This model is a key method for understanding megathrust earthquake mechanisms,

57 because direct measurements of plate boundary fault strength are quite rare and require

58 drilling into the deep décollement to obtain samples (e.g., Chester et al. 2013; Ujiie et al.

59 2013). According to this model, the tapered wedge geometry (slope angle $\alpha$ and basal

60 dip angle $\beta$ ) is determined by the strengths of the wedge materials and the effective

61 friction on the megathrust fault $\left(\mu_{b}{ }^{\prime}\right)$ (Fig. 1). Thus, the critical taper model allows the

62 geomechanical condition of a subduction wedge to be determined. This information can

63 be used to compare geomechanical conditions among different subduction zones (e.g.

64 Dahlen 1990) or to examine their spatial distribution within a single subduction zone

65 (e.g., Fagereng 2011; Koge et al. 2014) or temporal changes along a single profile (e.g., 
66 Wang et al. 2010; Wang and Hu 2006). Slope angle $\alpha$ can be calculated from the

67 bathymetry above the subduction wedge, which is typically observed by a multi-beam

68 echosounder onboard a ship. Generally, the bathymetry is obtained with a vertical error

69 on the order of several meters, so the accuracy with which $\alpha$ is determined is sufficient

70 for characterizing the wedge geometry. However, the subsurface geometry parameter

71 used in critical taper model calculations, namely, the basal dip angle $\beta$, requires further

72 consideration. In a depth-converted profile of seismic reflection data, the depth to the

73 plate boundary fault depends strongly on the velocity model used, and the accuracy of

74 the depth-conversion process affects the value obtained for the topographic parameter $\beta$.

75 Therefore, unless only highly accurate depth-converted profiles are used to calculate

76 this critical taper model parameter, comparisons within and among wedges are likely to

77 be unreliable. On a scale of several kilometers, pre-stack depth migration (PSDM) data

78 or, at larger scale, a cross section of the velocity structure combined with refraction data

79 can be used for accurate determination of $\beta$ for the critical taper model. However,

80 highly accurate PSDM data or seismic reflection profiles are often not available because

81 they require more processing time and are more costly to process than a simple 
82 depth-converted profile. As a result, the number of accurate cross sections available for

83 a critical taper analysis is often insufficient to reveal detailed along-strike variations of

84 frictional properties in subduction zones.

85 2. Revisiting, validating, and improving critical taper theory We first review formulations of Coulomb wedge/critical taper theory. All of

87 the formulas are based on a non-cohesive wedge model, which assumes non-viscosity

88 (Dahlen 1984). According to the Mohr-Coulomb failure criterion, $\tau=\sigma \cdot \tan \phi+C$,

89 where $\tau$ is shear stress, $\sigma$ is vertical stress, $\phi$ is the internal friction coefficient (also

90 expressed as $\mu$, the coefficient of internal friction averaged over the wedge), and $C$ is the

91 cohesion force. Because internal friction forces are proportional to vertical stress

92 whereas cohesion forces are independent of vertical stress, the cohesion term can be

93 neglected when considering huge geological structures with large $\sigma$. Thus, the

94 noncohesive critical taper model is valid in the entire wedge. Next, we theoretically verify the effect of the basal dip angle $\beta$ on the

96 calculation of effective friction $\mu_{b}{ }^{\prime}$ and show that the effect of $\beta$ becomes small when the

97 pore fluid pressure in the subduction zone is high. Hence, we propose that basal friction 
98 in subduction zones can be inferred from only the slope angle $\alpha$ determined from the

99 bathymetry.

2.1 Revisiting critical taper theory: Overview of the critical taper model to obtain

101 the effective coefficient of basal friction

104 the wedge geometry $(\alpha$ and $\beta$ ) is constrained by the balance between wedge strength and

105 effective friction $\mu_{b}{ }^{\prime}$ (e.g., Adam and Reuther 2000).

108 Reuther 2000; Wang and Hu 2006; Wang et al. 2010, 2019) (Fig. 2). In the critical taper

$$
\alpha^{\prime}=\tan ^{-1}\left[\left(\frac{1-\rho_{w} / \rho}{1-\lambda}\right) \tan \alpha\right]
$$

112 where $\alpha$ is a parameter obtained from the bathymetry/seismic profile, $\rho$ is wedge

113 sediment density, $\rho_{w}$ is fluid density, and $\lambda$ is the pore fluid pressure ratio. Then, the 
114 uniform angle between the most compressive principal stress axis $\sigma_{1}$ and the upper

115 slope, $\psi_{0}$ (see Fig. 1), is calculated as,

$$
\psi_{0}=\frac{1}{2} \sin ^{-1}\left(\frac{\sin \alpha^{\prime}}{\sin \phi}\right)-\frac{1}{2} \alpha^{\prime}
$$

116 where $\phi$ is the angle of internal friction within the wedge. Because along-strike stresses

117 are not considered in the critical taper model, the following simple geometric relation is

118 applicable (Fig. 1):

$$
\alpha+\beta=\psi_{b}-\psi_{0}
$$

119 where $\psi_{b}$ is the angle between $\sigma_{1}$ and the basal plane. Then, the effective coefficient

120 of basal friction $\left(\mu_{b}{ }^{\prime}\right)$ is obtained from the Mohr-Coulomb failure criterion $\tau$ and the

121 stress balance of the basal condition as

$$
\mu_{b}^{\prime}=\frac{\tan 2 \psi_{b}}{\csc \phi \sec 2 \psi_{b}-1}
$$

To draw the limb of the cross plot between $\mu_{b}{ }^{\prime}$ and $\lambda$, we set $\lambda$ to range

123 between 0 and 1 (Fig. 2). The left limb of the critical state curve represents

124 extensionally critical states, and the right limb represents compressively critical states.

125 Then, under the assumption that $\lambda$ is constant, we can obtain $\mu_{b}{ }^{\prime}$ from the intersection of

$126 \lambda$ and the critical state curve calculated earlier. 
$1281000 \mathrm{~kg} / \mathrm{m}^{3}$, internal friction angle $\varphi=34^{\circ}$, and $\lambda=0.88$ (Lallemand et al. 1994) (Fig. 2),

$129 \mu_{b}{ }^{\prime}$ can be determined from the intersection of $\lambda=0.88$ with the critical state curve

130 (Wang et al. 2019). Because the prism wedge in subduction zones should be in a

131 constant compressively critical state just before failure, we focus on only the

132 intersection with the right limb (representing compressively critical states). Thus, in this

133 example, we obtain $\mu_{b}{ }^{\prime}=0.06$. For more details than are provided in this simple review,

134 please see the cited studies.

1352.2 Validation and improvement: Effects of the geometric parameters on $\boldsymbol{\mu}_{\boldsymbol{b}}{ }^{\prime}$

136 In this study, we examined the sensitivity of the calculated $\mu_{b}{ }^{\prime}$ to the assumed

$137 \alpha$ and $\beta$ values to investigate how their accuracy affects the estimation of $\mu_{b}{ }^{\prime}$. We used

138 the mean subduction zone parameter values in the example described in section 2.1 and

139 changed the values of $\alpha$ and $\beta$ to see how $\mu_{b}{ }^{\prime}$ varied. The states of the frontal wedge with

$140 \alpha=5^{\circ}$ and $\beta=1^{\circ}$ or $\beta=5^{\circ}$ are shown in Fig. 3A; in Fig. 3B both $\alpha$ and $\beta$ are varied

141 from $1^{\circ}$ to $5^{\circ}$. We allowed $\beta$ to range from $1^{\circ}$ to $5^{\circ}$ because that range includes the basal

142 dip angle of most subduction zones (Lallemand et al. 1994; Wang et al. 2006). Here, 
143 since $\mu_{b}{ }^{\prime}$ cannot be determined when $\alpha=\beta=0$, those results were removed.

145 that $\beta$ has little influence on the estimation of $\mu_{b}{ }^{\prime}$ when the pore fluid pressure is high.

146 The change in $\beta$ (from $1^{\circ}$ to $5^{\circ}$ ) dominantly accounts for the change in the width of the

147 critical state curve (i.e., the angle between its limbs) between the two states illustrated in

148 Fig. 3A. When $\lambda$ is high, the intersection between $\lambda$ and the right limb of the critical

149 state curve is near the curve peak. Therefore, the change in the width due to a change in

$150 \beta$ has only a slight effect on $\mu_{b}{ }^{\prime}$. In typical subduction zones, $\lambda$ is high $(\sim 0.88)$

151 (Lallemand et al. 1994), so the effect of $\beta$ should be regarded as a small one. Moreover,

152 this finding is also favorable in terms of the accuracy of $\mu_{b}{ }^{\prime}$ obtained by applying the

153 critical taper theory, because the seismic profile depth used to calculate $\beta$ depends on

154 the velocity model/structure of the seismic profile, which is often not obtained with high

155 accuracy for reasons of time and money. Moreover, the number of available profiles is

156 also important to obtain the distribution of frictional properties by applying critical taper

157 theory. Thus, because $\beta$ must be obtained from depth-converted profiles with low

158 accuracy, the resulting error is large (Koge et al. 2014). In contrast, $\alpha$ can be determined 
159 with negligible error. The seafloor depth, which is used to calculate $\alpha$, is mostly based

160 on multibeam data and the sound velocity profile of seawater. These can be acquired

161 with high accuracy by conductivity/temperature/depth (CTD) measuring systems, or by

162 deploying expendable bathythermograph (XBT) or XCTD instruments, which generally

163 have a vertical error on the order of several meters. Therefore, from this perspective, $\alpha$

164 can be obtained with negligible error. The more significant factor influencing the error

165 of $\alpha$ is whether the obtained cross-section is aligned with the direction of maximum

166 slope. However, if the deviation from the maximum slope direction is no more than $18^{\circ}$,

167 the error in $\alpha$ will be less than 5\% [see Additional file 1]. Therefore, $\alpha$ can reliably be

168 obtained with high accuracy.

169 Under high pore fluid pressure conditions such as those in the mean

170 subduction zone, the influence of $\beta$ on the calculation of $\mu_{b}{ }^{\prime}$ should be small enough to

171 ignore. Thus, the $\alpha$ variation can be used to approximate the relative along-trench variation of $\mu_{b}{ }^{\prime}$, and data accuracy is improved. In this first step, we considered as an example the mean conditions described in section 2.1 (Fig. 3B and Table 1).

174 The next step is to determine quantitatively under what conditions $\beta$ can be ignored and 
175 the $\alpha-\mu_{b}{ }^{\prime}$ approximation can be used. We used linear multiple regression analysis, a

176 statistical method that can be used to predict the value of a variable (the response

177 variable) from the value of two or more other variables (explanatory variables), to

178 determine whether $\alpha$ or $\beta$ affects the effective friction coefficient $\mu_{b}{ }^{\prime}$. Here, we used $\alpha$

179 and $\beta$ as explanatory variables and $\mu_{b}{ }^{\prime}$ as the response variable. We conducted this

180 analysis with the stats-model API in Python (Seabold and Perktold 2010). The obtained

181 regression equation is characterized by the coefficients of $\alpha$ and $\beta$ ( $A$ and $B$,

182 respectively) and the coefficient of multiple determination $R^{2}$. To evaluate the relative

183 influence of $\alpha$ and $\beta$ on $\mu_{b}$ ', we also defined the parameter "weight of alpha" (WOA) $=$

$184 \mathrm{~A} /(\mathrm{A}+\mathrm{B})$. For the mean subduction zone, we obtained $R^{2}=0.99$ and $\mathrm{WOA}=77.50 \%$.

185 Thus, the goodness of fit of the regression equation, indicated by $R^{2}$, was high, and the

186 contribution of $\alpha$ to $\mu_{b}{ }^{\prime}$ was also high at $77.50 \%$.

187 Next, to determine whether $\beta$ can be neglected in most subduction zones, we

188 considered potential ranges of $\lambda$ and $\varphi$ in nature $\left(\lambda=0-1, \varphi=20-39^{\circ}\right)$, and then

189 calculated WOA and $R^{2}$ for all combinations of $\lambda$ and $\varphi$ in these ranges (Fig. 4, raw data

190 in Additional file 2). For example, using mean subduction wedge values of 21 
191 representative trenches (Lallemand et al. 1994), $(\lambda, \varphi)=\left(0.88,34^{\circ}\right)$, and WOA $=$

$19278.02 \%$. Of course, in some exceptional subduction zones, such as at the Sunda and

193 Makran trenches, $\lambda$ is small (Wang and $\mathrm{Hu}$ 2006), so the appropriateness of the

194 application of the $\alpha-\mu b^{\prime}$ approximation needs to be considered carefully. For more

195 example, at the toe of the Japan Trench, Kimura et al. (2012) and Wang et al. (2019)

196 assumed the following parameters: $(\lambda, \varphi)=\left(0.8,21.8^{\circ}\right)$ and $(\lambda, \varphi)=\left(0.95,36^{\circ}\right)$,

197 respectively. Given that under these conditions, $\mathrm{WOA}=79.86 \%$ and $88.54 \%$,

198 respectively (Fig. 4), in the toe of the Japan Trench, the frictional variation in the wedge

199 can be roughly regarded as determined by $\alpha$ alone. Therefore, if the WOA of the

200 targeted subduction zone is sufficiently high, frictional conditions along the plate

201 interface can be obtained by using $\alpha$ alone.

202 3. Application example of the $\alpha-\mu_{b}{ }^{\prime}$ approximation to the Japan Trench

203 Through our review and verification of the critical taper model, we found that

$204 \beta$ can be ignored not only when $\lambda$ is high but also when WOA is high, owing to either

205 high $\lambda$ or low $\varphi$ (Fig. 4). Thus, in our approximation, the spatial variation in the slope

206 angle $\alpha$ is an indicator of the variation in the effective basal friction $\mu_{b}{ }^{\prime}$, and, we can use 
only bathymetry data to obtain the distribution of the friction coefficient within a single

208 subduction zone. Here, we apply this approximation to the Japan Trench. The Japan

209 Trench is suitable for the application of this method because, as shown in section 2.2,

210 WOA is high in the toe portion of the wedge and the friction coefficient along the plate

211 interface can thus be estimated from only $\alpha$, as well as because a rupture occurred near

212 the trench axis during the 2011 Tohoku-Oki earthquake (Mw 9.0). Therefore, by

213 comparing the distribution of $\alpha$ which should reflect that of $\mu_{b}{ }^{\prime}$ in Japan Trench, the

214 question of why such coseismic rupture occurred in specific area can be addressed.

216 grid data of Kishimoto (2000), focusing on the shallow portion within a horizontal

217 distance of $25 \mathrm{~km}$ from the trench axis, and obtained the distribution of $\alpha$, interpreted as

218 the relative friction distribution, on the shallow megathrust (Fig. 5, Table 2). As a result,

219 using bathymetric profiles and slope angles obtained by modifying GMT/MATLAB

220 code as described by Wessel and Luis (2017), we accurately obtained the along-strike

221 distribution of $\mu_{b}{ }^{\prime}$ on the shallow plate boundary fault at 71 points (instead of at only a

222 dozen points or less, as is typical in applications of critical taper theory). 
224 corresponds to the coseismic slip distribution of the 2011 Tohoku-Oki earthquake

225 (Chester et al. 2013). This result suggests large fault rupture in the low- $\alpha$ segment have

226 occurred, causing the slip to propagate to the shallow portion of the plate boundary fault,

227 because of the low friction there. And it lead to the huge tsunami (e.g. Ide et al., 2011).

228 In contrast, the south and north ends of the coseismic slip zone are relatively

229 high-friction areas. As a result, the slip could not propagate to these other segments

230 because the high friction acted as a barrier. Therefore, the low friction in the shallow

231 area can be considered to be the cause of the huge tsunami. In addition, the low- $\alpha$

232 segment identified here approximately corresponds to the central segment along the

233 Japan Trench $\left(\sim 37^{\circ}-39^{\circ} \mathrm{N}\right)$ inferred from the distribution of seismic activity detected by

234 the S-net ocean-bottom seismograph network (Nishikawa et al. 2019). Low-friction conditions might prevail generally along the Japan Trench margin, except in regions of high friction caused by the recent subduction of a seamount

237 (Mochizuki et al. 2008) or the presence of petit-spot volcanoes (Hirano et al. 2006).

238 Because $\mu_{b}{ }^{\prime}$ depends on both $\lambda$ and $\varphi$, it is not possible to determine whether variation in 
$239 \alpha$ (i.e., relative $\mu_{b}{ }^{\prime}$ ) is due to a change in physical properties or to a change in pore fluid

240 pressure. Although here we cannot separate the effect of physical properties from that of

241 pore fluid pressure on $\alpha$, both effects are reflected in the strength of the megathrust.

\section{4. Conclusion} We presented an approach to the application of the critical taper model that,

244 intriguingly, has the potential to advance our ability to characterize basal friction along

245 the shallow plate interface in subduction zones. First, we reviewed the critical taper

246 model formulas used for calculating the effective coefficient of basal friction $\mu_{b}^{\prime}$. We

247 found that in most subduction zones, the effect of $\beta$ on basal friction can be regarded as

248 slight, especially when WOA is high, which occurs when $\lambda$ is high or $\varphi$ is low. The

249 spatial variation of $\alpha$ can be easily obtained with high accuracy from bathymetry data

250 obtained by multi-beam observation. Even in areas where observation is difficult, there

251 are ETOPO1 (Amante and Eakins 2009) or other global datasets obtained by the

252 satellites, most of which are free to access and also have a vertical error of only a few

253 tens of meters (Varga and Bašić 2015). Note that these global data set based on

254 satellite observations, so the vertical error order is a little larger. Therefore, by applying 
this approximation, the frictional distribution in subduction zones can now easily be evaluated.

258 resolution of the along-trench distribution of $\mu_{b}{ }^{\prime}$ determined on a shallow megathrust.

259 By applying our approach to the Japan Trench, we showed that the seafloor slope angle

260 (relative $\mu_{b}{ }^{\prime}$ ) is systematically smaller within the area of large coseismic shallow slip

261 during the 2011 Tohoku-Oki earthquake than it is in areas to the south and north, where

262 little coseismic slip has been imaged. In the future, a global study is needed to examine

263 the correlation between frictional conditions along the plate interface as revealed by the

264 seafloor topography and seismicity and improve our understanding of the connection

265 between earthquake physics and tectonics. Our critical taper results are given in

266 Additional file 3, attached. By referring to this file, the coefficient of effective friction on the plate boundary fault can be determined if the geomechanical parameters $\lambda, \varphi, \alpha$, and $\beta$ of the subduction zone are known. 
All data are available in the main text or in the supplementary materials.

Authors declare no competing interests.

\section{Funding}

HK was supported by JSPS KAKENHI Grant Number JP17K05687. JA

and JP are supported by JSPS KAKENHI Grant Number JP18H03732.

AM is supported by JSPS KAKENHI (Grant-in-Aid for Scientific

Research on Innovative Areas) Grant Number JP17H05321. SY is

supported by JSPS KAKENHI Grant Number 21H01189.

H. Koge mainly contributed to conceptualization, data curation, methodology, visualization, and writing of the original draft. J. Ashi and 

to write, review, and edit the paper.

\section{Acknowledgements and Endnotes}

290

A. Yamaguchi, G. Kimura, and A. Noda provided advice on

anonymous reviewers for their thoughtful reviews.

293

294 References

295 Adam J, \& Reuther C D (2000) Crustal dynamics and active fault mechanics during

296 subduction erosion. Application of frictional wedge analysis on to the North Chilean

297 Forearc. Tectonophysics, 321, 297-325. doi:10.1016/S0040-1951(00)00074-3

298 Amante C, \& Eakins B W (2009) ETOPO1 1 Arc-Minute Global Relief Model:

299 Procedures, Data Sources and Analysis. NOAA Technical Memorandum NESDIS

$300 \quad$ NGDC-24, 19. doi:10.1594/PANGAEA.769615

301 Chester F M, Rowe C, Ujiie K, et al. (2013) Structure and composition of the

302 plate-boundary slip zone for the 2011 Tohoku-Oki earthquake. Science, 342, 1208 
304 Dahlen F A (1984) Noncohesive Critical Coulomb Wedges: an Exact Solution. Journal

305 of Geophysical Research, 89, 10125-10133. doi:10.1029/JB089iB12p10125

306 Dahlen F (1990) Critical Taper Model Of Fold-And-Thrust Belts And Accretionary

307 Wedges. Annual Review of Earth and Planetary Sciences, 18, 55-99.

308 doi:10.1146/annurev.earth.18.1.55

309 Davis D, Suppe J, \& Dahlen F A (1983) Mechanics of fold-and- thrust belts and

310 accretionary wedges. Journal of Geophysical Research, 88, 1153-1172.

311 doi:10.1029/JB088iB02p01153

312 Fagereng A (2011) Wedge geometry, mechanical strength, and interseismic coupling of

313 the Hikurangi subduction thrust, New Zealand. Tectonophysics, 507, 26-30.

314 doi:10.1016/j.tecto.2011.05.004

315 Hirano N, Takahashi E, Yamamoto J, et al. (2006) Volcanism in response to plate

316 flexure. Science, 313, 1426-1428. doi:10.1126/science.1128235

317 Ide S, Baltay A, Beroza, GC (2011) Shallow dynamic overshoot and energetic deep

318 rupture in the $2011 \mathrm{Mw} 9.0$ Tohoku-Oki earthquake. Science, 332(6036), 1426-1429. 
320 Kimura G, Hina S, Hamada Y, et al. (2012) Runaway slip to the trench due to rupture of

321 highly pressurized megathrust beneath the middle trench slope: The tsunamigenesis of

322 the 2011 Tohoku earthquake off the east coast of northern Japan. Earth and Planetary

323 Science Letters, 339-340, 32-45. doi:10.1016/j.eps1.2012.04.002

324 Kishimoto K (2000) Combined Bathymetric and Topographic Mesh Data: Japan 250m

325 Grid. Open File Rep. 353, 1-CD-ROM.

326 Koge H, Hamahashi M, Kimura G, et al. (2014) Friction properties of the plate

327 boundary megathrust beneath the frontal wedge near the Japan Trench: An inference

328 from topographic variation Multidisciplinary. Earth, Planets and Space, 66, 1-10.

329 doi:10.1186/s40623-014-0153-3

330 Lallemand S E, Schnürle P, \& Malavieille J (1994) Coulomb theory applied to

331 accretionary and nonaccretionary wedges: Possible causes for tectonic erosion and/or

332 frontal accretion. Journal of Geophysical Research: Solid Earth, 99, 12033-12055.

333 doi:10.1029/94jb00124

334 Lehner F K (1986) Comments on "Noncohesive critical Coulomb wedges: An exact 
solution” by F. A. Dahlen. Journal of Geophysical Research, 91, 793.

336

doi:10.1029/jb091ib01p00793

337 Mochizuki K, Yamada T, Shinohara M, et al. (2008) Weak interplate coupling by

338 seamounts and repeating M 7 earthquakes. Science, 321, 1194-1197.

339 doi:10.1126/science. 1160250

340 Nishikawa T, Matsuzawa T, Ohta K, et al. (2019) The slow earthquake spectrum in the

341 Japan Trench illuminated by the S-net seafloor observatories. Science, 365, 808-813.

342 doi:10.1126/science.aax5618

343 Seabold, Skipper, Josef Perktold. "statsmodels: Econometric and statistical modeling

344 with python.” Proceedings of the 9th Python in Science Conference. 2010.,

345 https://www.statsmodels.org/stable/index.html

346 Ujiie K, Tanaka H, Saito T, Tsutsumi A, Mori J, Kameda J, Brodsky E, Chester FM,

347 Eguchi N, Toczko S, Expedition 343 and 343T Scientists (2013) Low coseismic shear

348 stress on the Tohoku-Oki megathrust determined from laboratory experiments. Science,

349 342, 1211-1214. doi:10.1126/science.1243485

350 Varga M, \& Bašić T (2015) Accuracy validation and comparison of global digital 
351 elevation models over Croatia. International Journal of Remote Sensing, 36, 170-189.

352 doi:10.1080/01431161.2014.994720

353 Wang K, \& Hu Y (2006) Accretionary prisms in subduction earthquake cycles: The

354 theory of dynamic Coulomb wedge. Journal of Geophysical Research: Solid Earth,

$355 \quad 111$, doi:10.1029/2005JB004094

356 Wang K, Brown L, \& Hu Y (2019) Stable Forearc Stressed by a Weak Megathrust :

357 Mechanical and Geodynamic Implications of Stress Changes Caused by the $M=9$

358 Tohoku - Oki Earthquake Journal of Geophysical Research : Solid Earth, 6179-6194.

359 doi:10.1029/2018JB017043

360 Wang K, Hu Y, von Huene R, et al. (2010) Interplate earthquakes as a driver of shallow

361 subduction erosion. Geology, 38, 431-434. doi:10.1130/G30597.1

362 Wessel P, Luis J F (2017) The GMT/MATLAB Toolbox. Geochemistry, Geophysics,

363 Geosystems, 18, 811-823. doi:10.1002/2016GC006723

364

365 

forearc wedge in the Japan Trench (modified from Kimura et al. 2012). $\alpha$ : slope angle,

$370 \beta$ : basal dip angle $\beta, \mu_{b}{ }^{\prime}$ effective friction on the megathrust fault. The frontal wedge

371 area is between the blue broken lines. B Diagram showing the self-similar growth of a 372 bulldozer wedge (modified from Dahlen 1990).

Figure 2. Cross plot between the pore fluid pressure ratio $\lambda$ and basal friction $\mu_{b}$,

in the wedge. All extensionally critical states form the left limb of the critical state curve, and all compressively critical states form the right limb. The stable region is under the curve (white). The straight-line intersecting the critical state curve represents constant $\lambda$. 
different values of $\beta$. $\mathbf{B}$ Variation in $\mu_{b}$ ' when $\alpha$ and $\beta$ are varied from $1^{\circ}$ to $5^{\circ}$, assuming mean subduction wedge conditions.

Figure 4. Heat map for weight of alpha (WOA). The closer WOA is to $100 \%$, the more friction can be considered in terms of seafloor topography alone, because $\mu_{b}$ ' can be determined from $\alpha$ alone. Conditions in the Japan Trench according to Kimura et al. (2012) and Wang et al. (2019) are shown by the two white squares. (red contours). The epicenter of the Tohoku-Oki earthquake is shown by a yellow star, and the red lines show the positions of bathymetric profiles used to obtain $\alpha$. $\mathbf{B}$ The distribution of $\alpha$ along the Japan Trench. The red area corresponds to the coseismic slip area in the map in $\mathbf{A}$ (Chester et al. 2013). The orange bar indicates the peak of the $\alpha$ distribution histogram. 
401 Table 1. Values of $\boldsymbol{\mu}_{\boldsymbol{b}}$ 'obtained by varying $\boldsymbol{\alpha}$ and $\boldsymbol{\beta}$ from $\mathbf{1}^{\circ}$ to $\mathbf{5}^{\circ}$. The left table was

402 calculated by assuming mean subduction wedge conditions. The right table was

403 calculated using conditions in the outer wedge of the Japan Trench.

405 Table 2 Slopes measured along bathymetric profiles on the landward side of the

406 Japan Trench.

407

408 Additional files

409 Additional file 1: Supplemental text.pdf

410 Additional file 2: result_ols.csv; raw data for WOA plot (Fig. 4)

411 Additional file 3: result_ct.csv; raw results for critical taper parameters. 
Figures

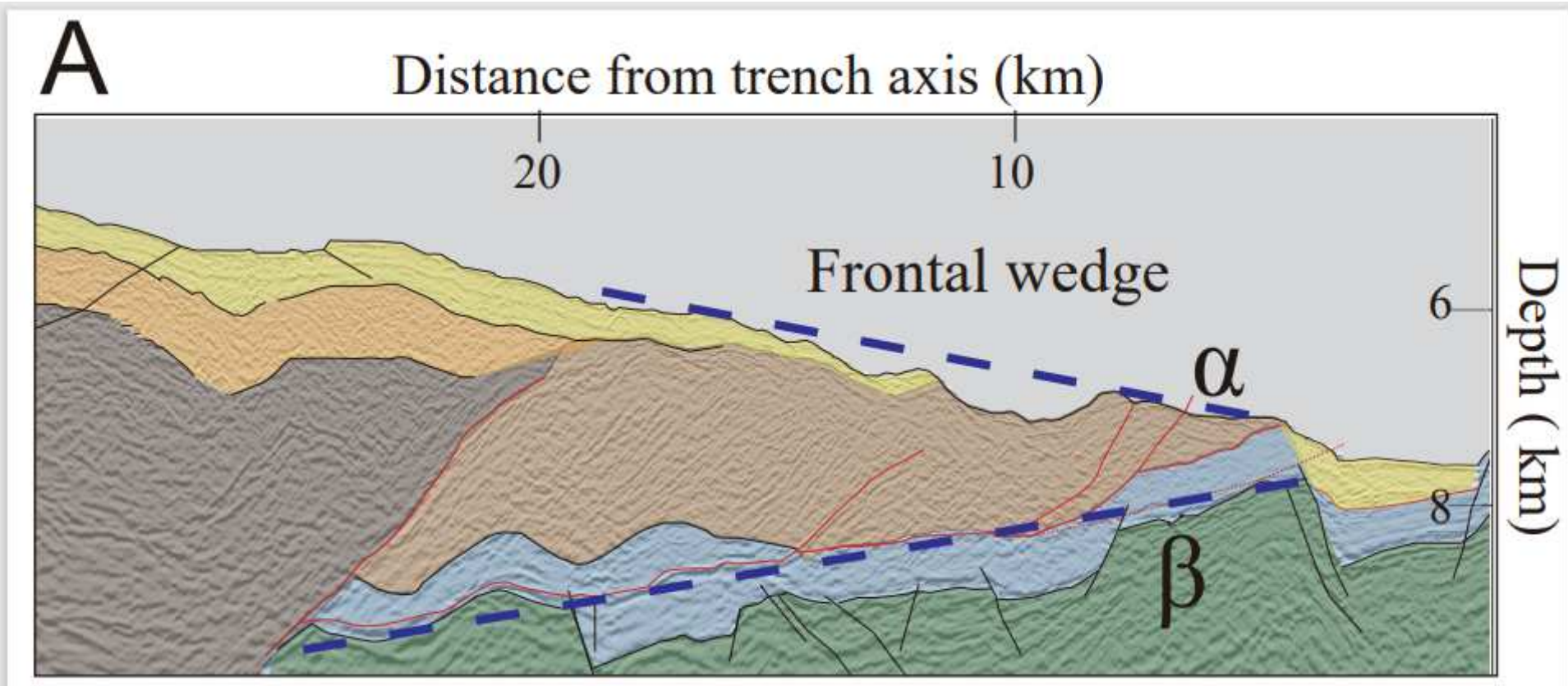

B

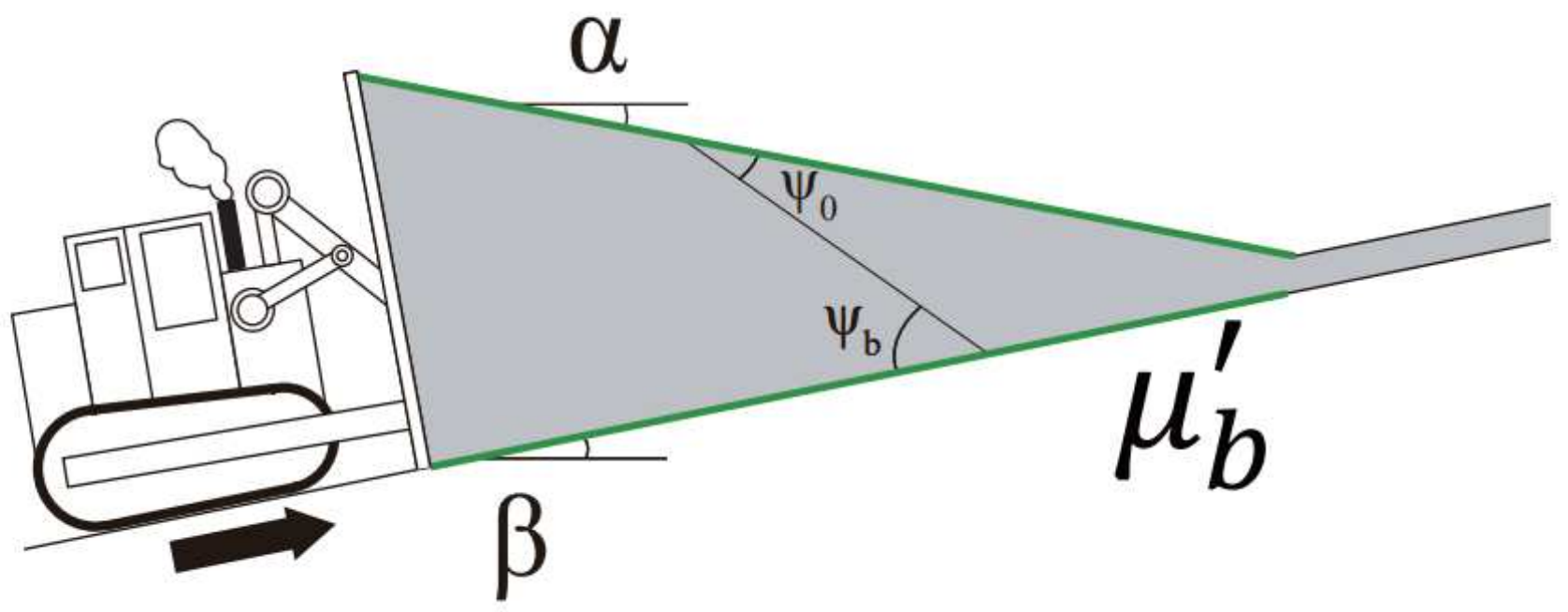

Figure 1

Schematic illustration of the critical taper model. A Cross section of the forearc wedge in the Japan Trench (modified from Kimura et al. 2012). a: slope angle, $\beta$ : basal dip angle $\beta, \mu b$ ' effective friction on the megathrust fault. The frontal wedge area is between the blue broken lines. B Diagram showing the selfsimilar growth of a bulldozer wedge (modified from Dahlen 1990). 


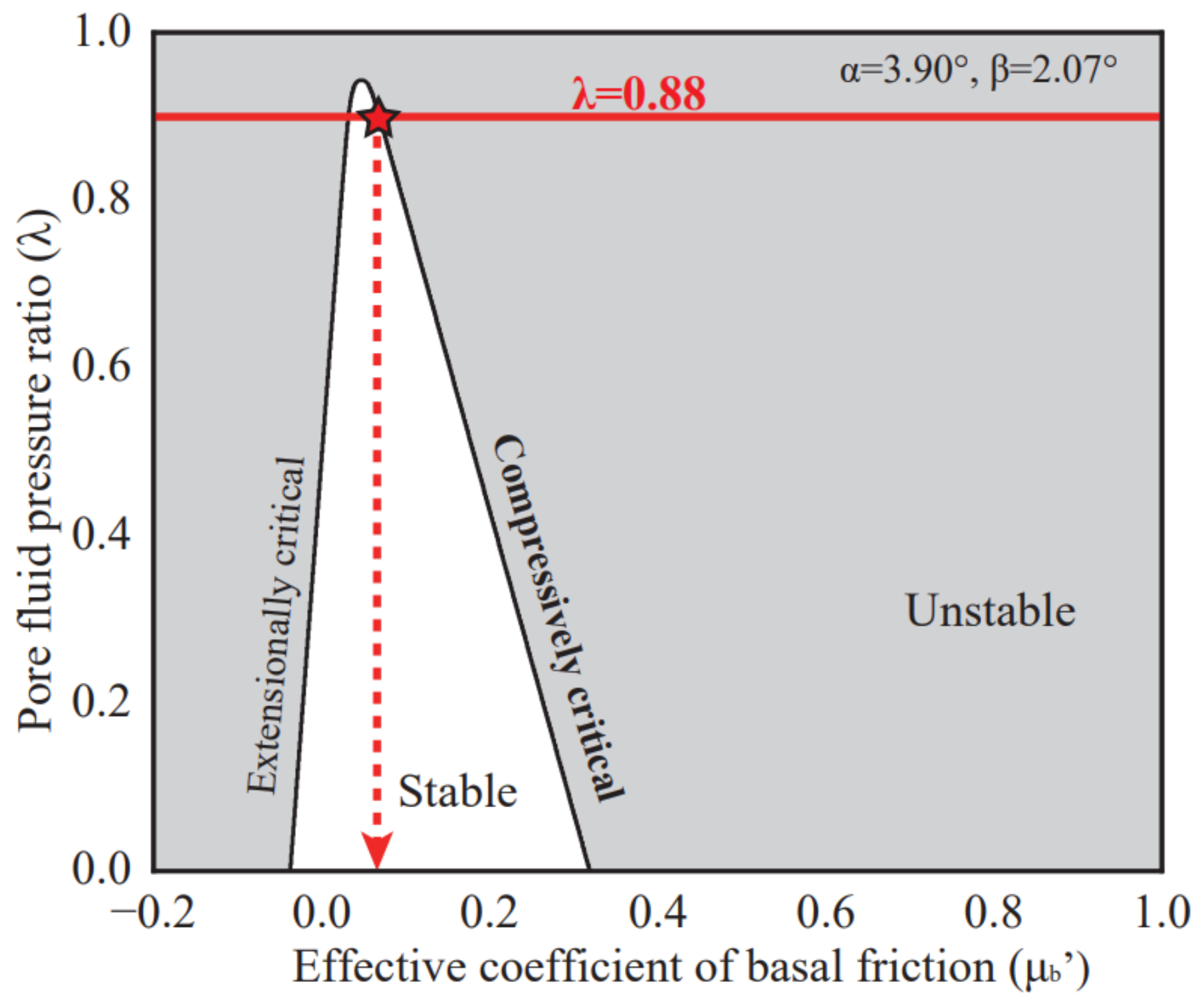

Figure 2

Cross plot between the pore fluid pressure ratio $\lambda$ and basal friction $\mu b^{\prime}$ in the wedge. All extensionally critical states form the left limb of the critical state curve, and all compressively critical states form the right limb. The stable region is under the curve (white). The straight-line intersecting the critical state curve represents constant $\lambda$. 


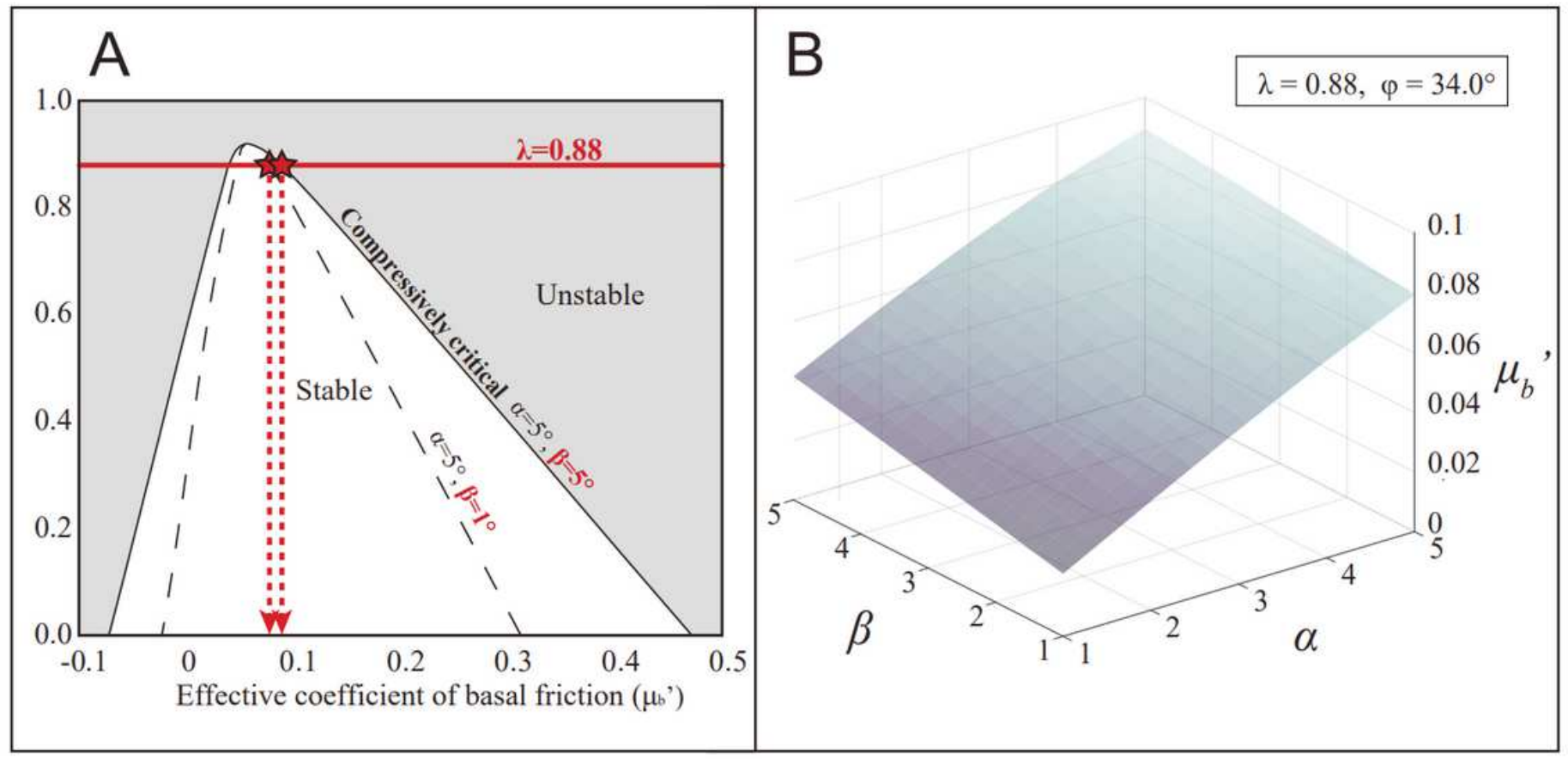

Figure 3

Considering the weight of $\beta$. A The mechanically critical value of a frontal wedge is controlled by the fluid pressure ratio within the prism $(\lambda)$ and the effective basal friction $\left(\mu b^{\prime}\right)$. The solid and broken lines represent the critical state curve for different values of $\beta$. B Variation in $\mu b^{\prime}$ when $a$ and $\beta$ are varied from $1^{\circ}$ to $5^{\circ}$, assuming mean subduction wedge conditions. 


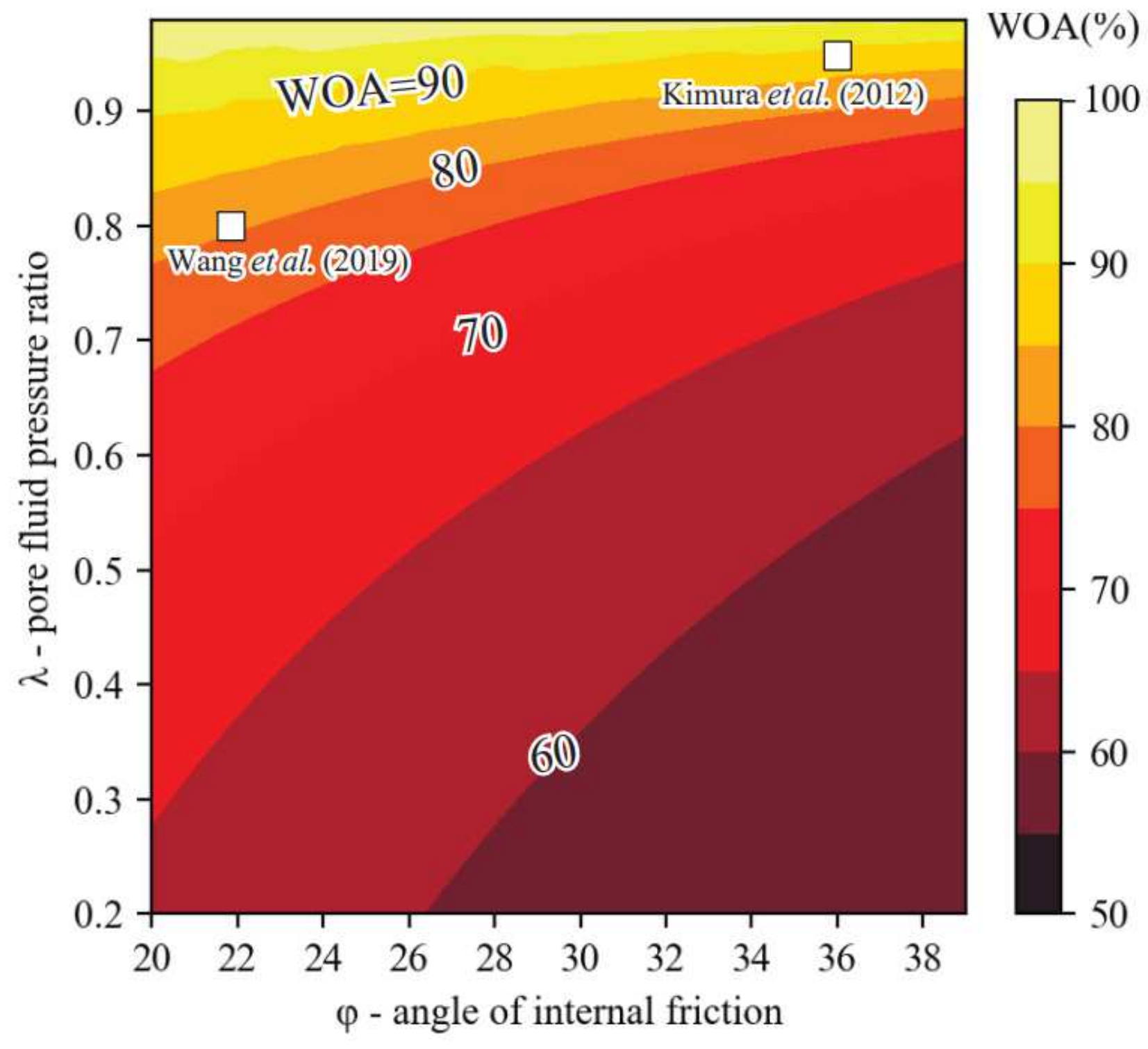

Figure 4

Heat map for weight of alpha (WOA). The closer WOA is to $100 \%$, the more friction can be considered in terms of seafloor topography alone, because $\mu b^{\prime}$ can be determined from a alone. Conditions in the Japan Trench according to Kimura et al. (2012) and Wang et al. (2019) are shown by the two white squares. 


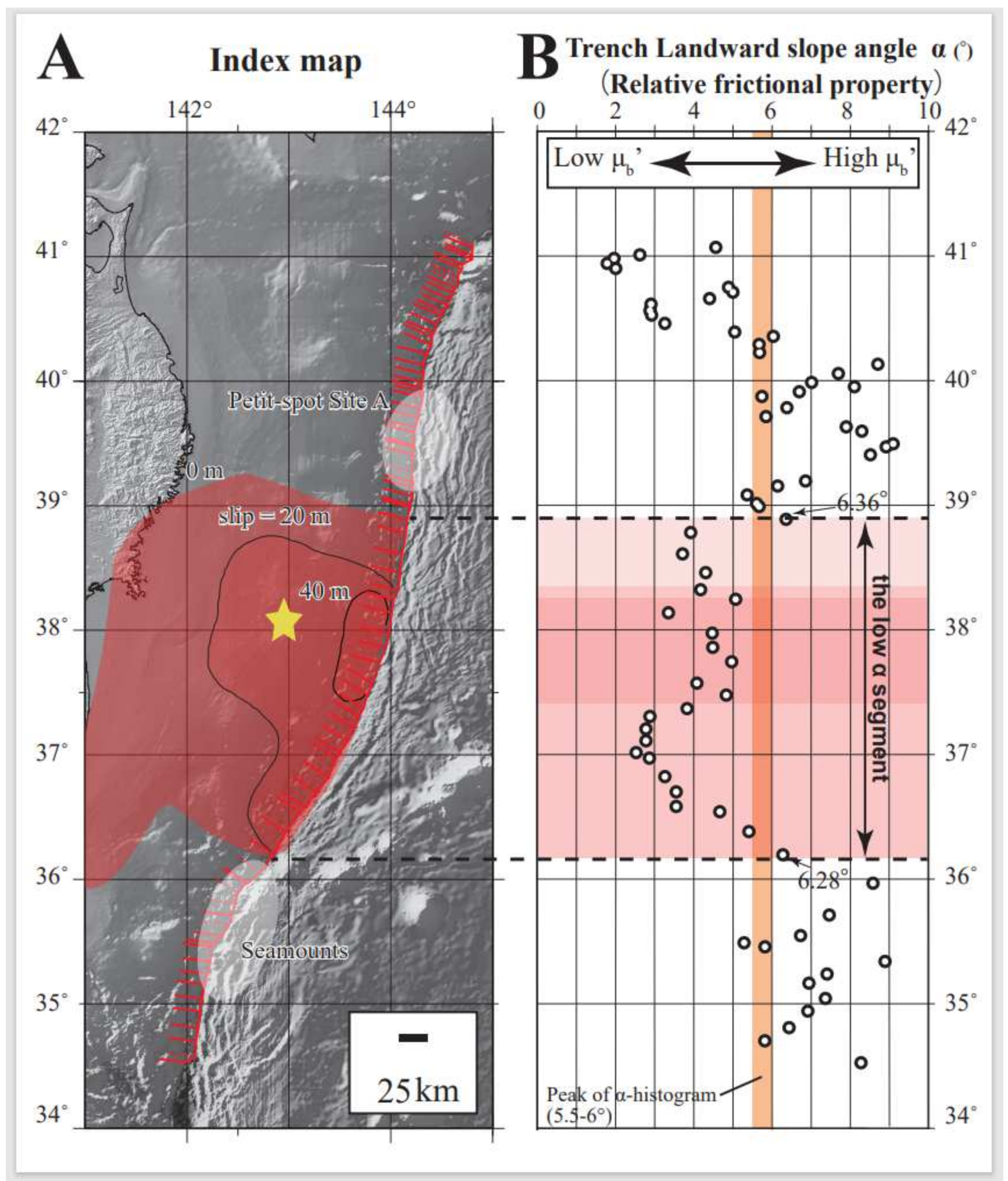

Figure 5

Comparison of the spatial variation of slope angle $a$ in the Japan Trench and the coseismic slip distribution. A Compiled coseismic slip along the Japan Trench (red contours). The epicenter of the Tohoku-Oki earthquake is shown by a yellow star, and the red lines show the positions of bathymetric profiles used to obtain $\mathrm{a}$. B The distribution of a along the Japan Trench. The red area corresponds to the 
coseismic slip area in the map in A (Chester et al. 2013). The orange bar indicates the peak of the a distribution histogram.

\section{Supplementary Files}

This is a list of supplementary files associated with this preprint. Click to download.

- FigureABSTRUCT.jpg

- Supplementarytext.pdf

- resultols.csv

- resultct.csv 